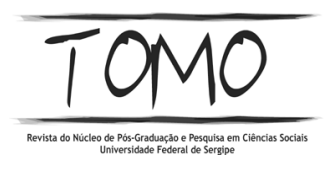

\title{
PROCESSO DE BOLONHIA: A REFORMA DO SISTEMA DE EDUCAÇÃO SUPERIOR EUROPEU
}

\author{
Clarissa Eckert Baeta Neves* \\ Leonardo Renner Koppe**
}

\section{RESUMO}

O artigo discute as transformações dos sistemas de educação superior na Europa a partir do Processo de Bolonha. Na primeira parte, faz-se uma análise do contexto histórico e social ressaltando os principais elementos que elevaram a educação superior a tema central na pauta da agenda de decisões das esferas políticas supranacionais européias. Na segunda parte são apresentadas as principais características desse processo, a partir dos diferentes Comunicados assinados pelos Ministros da Educação dos países que aderiram ao processo, destacando as principais linhas implementadas: adoção de um sistema baseado em ciclos; estabelecimento do sistema de transferência e acumulação de créditos; promoção da mobilidade; investimento na qualidade; criação do Espaço Europeu de Educação Superior.

Palavras-chave: Processo de Bolonha, Educação Superior, mobilidade.

* Professora do Programa de Pós-Graduação em Sociologia da Universidade Federal do Rio Grande do Sul. Coordenadora do Grupo de Estudos sobre Universidade/ GEU/UFRGS. Pesquisadora CNPq. FULBRIGHT Scholar 2007/2008.

** Professor de Gestão Cultural do Instituto Federal de Educação Ciência e Tecnologia SulRio-Grandense. Mestre em Sociologia e doutorando pelo Programa de Pós-Graduação em Sociologia da Universidade Federal do Rio Grande do Sul. Pesquisador do Grupo de Estudos sobre Universidade/ GEU/UFRGS. 


\section{ABSTRACT}

This article discusses the changes in European higher education systems after the Bologna Process. The first part presents its historical and social context highlighting the aspects which brought higher education to the fore of the European supranational agenda. The second part presents the main characteristics of the changes after the Communiqué's signed by European Ministers of Education who joined the process of reform: adoption of an educational system based on three cycles (bachelor, master and doctorate studies); establishment of a Credit Transfer and Accumulation System; facilitating mobility; improving quality; creation of the European Space for higher Education, among others.

Key words: Bologna Process, higher education, Europe, mobility. 


\section{INTRODUÇÃO}

Em 1998, diversos países europeus, representados pelos seus Ministros da Educação engajaram-se em um audacioso projeto com o objetivo de harmonizar os sistemas nacionais de educação superior. Esse projeto conhecido como Processo de Bolonha, conta hoje com a participação voluntária de 47 países europeus. O presente artigo aborda a origem e as principais características desse processo. É importante observar que os tratados da União Européia/UE especificavam que a educação era uma atividade sob jurisdição dos Estados membros e, portanto, não seria matéria de regulamentação pela União. Com isso, os sistemas de educação superior permaneciam à margem da integração européia, em que pese os importantes programas de apoio à mobilidade estudantil e de docentes na Europa como, por exemplo, os programas Sócrates ${ }^{1}$ e Erasmus² (Morhard, 2005).

Mudar esta situação foi o grande desafio que tomaram a si quatro Ministros responsáveis pela educação superior (da Grã-Bretanha, Alemanha, França e Itália), que se pronunciaram, em 1998, na Declaração da Sorbonne, a favor da criação de uma Área Européia de Educação Superior (European Area for Higher Learning).

Em 1999, essa iniciativa foi incluída na Declaração de Bolonha, criando o Espaço Europeu de Educação Superior, por adesão dos países signatários. Consequentemente, a política educacional não era mais uma pauta nacional, mas ação conjunta de diversas organizações (estatais, civis, empresariais e institucionais) no âmbito europeu para além da União Européia, com vistas a modificar os sistemas de educação superior (UK HE Europe Unit, 2005).

Bolonha representa hoje o movimento mais ousado de reforma da educação superior, mundo afora. São muitas as razões para isso, pois Bolonha é um projeto que aprofunda a integração em todos os planos e atividades dos países membros e representa:

O programa Sócrates foi criado em 1994 com o objetivo de promover a mobilidade através da educação. Em 2007 ele foi substituido pelo Lifelong Learning Programme 2007-2013.

2 Protocolo Erasmus ou Programa Erasmus foi estabelecido em 1987. É um programa de apoio interuniversitário de mobilidade de estudantes e docentes do ensino superior, entre estados membros da União Europeia e estados associados. Permite a alunos que estudem noutro país por um período de tempo entre 3 e 12 meses. 
a) o fato de que tenha sido uma decisão eminentemente política e tomada de cima para baixo, que passou a ser vista como inevitável e irreversível por todos os atores dos diferentes sistemas nacionais europeus;

b) a percepção da necessidade de aprofundar a integração dos sistemas nacionais como forma de aumentar as chances do bloco. A percepção de que a Europa, no seu conjunto, começara a perder a posição de prestígio e liderança acadêmica e cultural no mundo e que era necessário recobrar a atratividade do seu sistema de educação superior num cenário globalizado de competição de talentos;

c) a necessidade de ajustar as estruturas universitárias a um cenário de afirmação da sociedade do conhecimento em escala global e de competitividade econômica, baseada na permanente incorporação de conhecimentos ao processo produtivo;

d) o rompimento de uma longa tradição de modelos europeus, questionando-os quanto à eficiência e qualidade no novo cenário de exigências advindo com a globalização e o acirramento da competição entre os países desenvolvidos; o diagnóstico negativo no tocante à evasão, a demora na conclusão dos cursos, os altos custos e o conservadorismo das estruturas das instituições de Educação Superior/IES;

e) o diagnóstico de que era necessário apressar a qualificação e a entrada de jovens no mercado de trabalho para aumentar a produtividade e fazer frente ao progressivo envelhecimento da população.

Desde o final dos anos 1990 acentua-se o ritmo das reformas da educação superior na Europa, amparado, além do processo de Bolonha, também por duas outras iniciativas: a Estratégia de Lisboa ${ }^{3}$ (2000) e a Agenda de Modernização ${ }^{4}$ (2007). Essas iniciativas surgiram no âmbito da União Européia como projetos para a construção da Europa numa economia baseada no conhecimento. Um primeiro

3 Fonte: http://www.estatisticas.gpeari.mctes.pt/archive/doc/EstrategiaLisboa.pdf

4 Fonte: http://eur-lex.europa.eu/LexUriServ/LexUriServ.do?uri=CELEX:52006DC0208:EN:HTML 
relatório da Comissão Européia elaborado para o Conselho Europeu denominado de "Os objetivos futuros concretos dos sistemas educativos" 5 propõe algumas medidas a serem tomadas para tornar a Europa do Conhecimento uma realidade, como aumento dos gastos públicos e privados em educação superior, aumento da qualificação de professores, promoção da formação continuada (lifelong learning), aumento da atratividade dos sistemas de educação superior entre outros.

\section{O contexto histórico e social}

A compreensão do Processo de Bolonha, iniciado em 1999 requer, num primeiro momento, a compreensão do contexto histórico e social, no qual ele surge. É importante ressaltar os principais elementos que elevaram a educação superior à tema central na pauta da agenda de decisões das esferas políticas supranacionais européias.

Duas instituições são fundamentais para a compreensão desse processo de integração, a União Européia e o Conselho da Europa. Enquanto a experiência de cooperação e integração da União Européia serviu de base e de estímulo para a integração da educação superior, o Conselho da Europa orientou os limites político-territoriais dessa integração. As duas organizações podem ser entendidas como as esferas macro-políticas, ou supranacionais de decisão política européia. Mesmo que essas instituições não possuam poderes legais para a alteração de determinadas políticas setoriais (por exemplo, a educacional), suas recomendações exercem forte influência para o desenvolvimento de outros processos de decisão que podem levar à mudanças nas políticas nacionais.

A Declaração de Bolonha (1999) traz em seu parágrafo inicial como apresentação e justificativa para a proposta de reforma da educação superior, os progressos obtidos com a formação da União Européia. De acordo com o documento:

O processo europeu tem-se tornado uma realidade cada vez mais concreta e relevante para a União Européia e para os seus cidadãos,

5 Fonte: http://europa.eu/eur-lex/pt/com/rpt/2001/com2001_0059pt01.pdf 
graças às extraordinárias realizações dos últimos anos. As perspectivas de alargamento assim como as estreitas relações com os outros países europeus acrescem uma maior dimensão a esta realidade. Simultaneamente, temos vindo a testemunhar uma consciencialização crescente em largas faixas da esfera política, acadêmica e da opinião pública, da necessidade de criar uma Europa mais completa e abrangente, em especial no que respeita à construção e ao reforço das suas dimensões intelectual, cultural, social, científica e tecnológica (Declaração de Bolonha, 1999) ${ }^{6}$.

A União Européia (UE) atualmente conta com 27 países membros ${ }^{7}$, resultado de um processo de negociações e acordos de cooperação de países europeus, que iniciaram ao final da Segunda Guerra Mundial (1945).

A atuação da UE nos assuntos relacionados às questões, econômicas e políticas, configura-se em um dos seus principais objetivos. Em seguida ao artigo $1^{\circ}$ do Tratado que institui a Comunidade Européia ${ }^{8}$, o artigo $2^{\circ}$ destaca que:

A Comunidade tem como missão, através da criação da um mercado comum e de uma união econômica e monetária e da aplicação das políticas ou ações comuns a que se referem os artigos 3.o e 4.o, promover, em toda a Comunidade, o desenvolvimento harmonioso, equilibrado e sustentável das atividades econômicas, um elevado nível de emprego e de proteção social, a igualdade entre homens e mulheres, um crescimento sustentável e não inflacionista, um alto grau de competitividade e de convergência dos comportamentos das economias, um elevado nível de proteção e de melhoria da qualidade do ambiente, o aumento do nível e da qualidade de vida, a coesão econômica e social e a solidariedade entre os EstadosMembros (Tratado que institui a Comunidade Européia, Artigo $2^{\circ}$ ).

6 http://www.cnaves.pt/DOCS/Diversos/declaracaodebolonha.pdf, Anexo 1, consultado em 03/11/2008.

7 Site da União Européia: http://europa.eu/abc/panorama/index_pt.htm, consultado em 03/11/2008.

8 http://eur-lex.europa.eu/pt/treaties/dat/12002E/htm/C_2002325PT.003301.html\#anArt2, consultado em 03/11/2008. 
Os acordos estabelecidos no âmbito legislativo da União Européia, portanto, promoveram uma série de objetivos comuns de cooperação e integração dos países europeus, seja no campo econômico, como político, permanecendo excluídos desses acordos, as disposições legais sobre os sistemas educativos dos países membros. A educação permanecia como um tema legislativo de responsabilidade dos Estados membros e não da competência da União Européia.

A integração econômica e política no âmbito da União Européia acabou incentivando a necessidade de uma transformação também no âmbito da organização da educação superior dos países envolvidos, tendo como conseqüência direta, o desenvolvimento do Processo de Bolonha.

O Conselho da Europa é a outra instituição fundamental na concretização do Processo de Bolonha. É uma organização política distinta da União Européia e que congrega 47 Estados europeus (e mais um país candidato, Bielorrússia). Essa organização foi criada em 1949 tendo por fins ${ }^{9}$ :

- Defender os direitos do homem e a democracia parlamentar, e assegurar a preeminência do direito;

- Concluir acordos à escala do continente para harmonizar as práticas sociais e jurídicas dos Estados membros;

- Favorecer a tomada de consciência da identidade européia, fundada sobre valores partilhados que transcendem as diferentes culturas.

O Conselho da Europa foi responsável por acordos relevantes para a educação superior de seus países membros. Da mesma forma que a União Européia, o Conselho da Europa não possui poderes para determinar ou influenciar a organização dos sistemas de educação dos países participantes. No entanto, esta foi a principal organização que promoveu convenções entre os países europeus em relação à educação superior. Dentre os documentos do Conselho da Europa ${ }^{10}$ destacam-se as seguintes convenções sobre a educação superior:

9 Fonte: http://www.coe.int/t/pt/com/about_coe/

10 Fonte: http://conventions.coe.int/treaty/Commun/ListeTraites.asp? CM $=8 \& C L=E N G$, consultado em 03/11/2008. 
-Convenção Européia de Equivalência de Diplomas de Ensino para Admissão para Universidades. (1953);

-Convenção Cultural Européia. (1954);

-Convenção Européia de Equivalência de Períodos de Estudos

Universitários. (1956);

-Convenção Européia de Reconhecimento Acadêmico de Qualificações

Universitárias. (1959);

-Convenção Européia de Equivalência Geral de Períodos de Estudos Universitários. (1990);

-Convenção de Reconhecimento de Qualificações Concernentes à Educação

Superior na Região (Area) Européia. (1997).

Pode-se perceber que os primeiros acordos implantados pelo Conselho da Europa deram-se nas décadas de 1950 e 1960, tendo por objetivos o reconhecimento de estudos, em particular associados à aprendizagem de línguas estrangeiras. Na década de noventa, novos acordos são assinados, sobretudo para ampliar o alcance e as possibilidades de se estudar em mais de um país e obter o reconhecimento dos estudos feitos (Grosjean, 1999). Essa percepção da necessidade de ampliar os limites da educação superior, em especial ampliar/ ultrapassar os limites nacionais, gerou novas iniciativas conjuntas dos países europeus (Declaração de Bolonha, 1999).

A trajetória dessas duas instituições, em especial as conseqüências de suas iniciativas (acordos, convenções e projetos) para a economia e a política européia, foi essencial para a formação do contexto favorável à reforma da educação superior européia no final do século XX. Pode-se afirmar que sob a perspectiva da integração dos países europeus, a harmonização dos sistemas de educação superior era uma possibilidade que começou a tornar-se realidade com o Processo de Bolonha.

\section{O Processo de Bolonha}

A Declaração de Sorbonne (1998) tornou-se conhecida como o documento inicial da reforma européia da educação superior, no qual 
foi lançada a "declaração-conjunta" (Joint Declaration) para os demais países europeus com o intuito de promover a harmonização das estruturas dos sistemas de educação superior. As propostas apresentadas, fundamentalmente foram:

Os sistemas de educação superior da Europa deveriam ser coerentes e compatíveis para reforçar o reconhecimento de qualificações e a competitividade internacional da educação superior da Europa;

Favorecer a criação de uma "Área Européia de Educação Superior" (European Area for Higher Learning).

A Declaração-Conjunta de Sorbonne mobilizou ministros da educação europeus, instituições e associações relacionadas à educação superior, para a realização de um novo encontro no ano seguinte.. De acordo com Witte, essa carta teve uma grande repercussão e contribuiu para a reunião ocorrida em Bolonha em 1999, com a presença de 29 países europeus (Witte, 2006).

Os documentos produzidos no âmbito do Processo de Bolonha (Declarações e Comunicados dos Ministros da Educação 1998, 1999, 2001, 2003, 2005, 2007 e 2009; Trends Reports da EUA, 1999, 2001, 2003, 2005 e 2007) sintetizam uma série de intenções que envolvem o processo de reforma das universidades, frente às transformações decorrentes do processo de globalização.

A figura 1, a seguir, revela as principais decisões tomadas em cada encontro do processo de Bolonha realizado desde 1998 até 2009. Essa linha do tempo foi retirada de um documento do Observatório Eurydice, com sede em Bruxelas que realiza diversas análises sobre a educação dos países europeus. Pode-se perceber que de 1999 até 2005 foram sistematicamente incorporadas novas demandas à proposta inicial do processo, que consistia em uma estrutura comum de qualificação, um sistema baseado em ciclos de formação e promoção da mobilidade de estudantes e professores. Já em 2007 e 2009 são reforçadas as metas de mobilidade, qualidade, compromisso com a dimensão social, educação comtinuada. 
Figura 1: Linha do tempo do Processo de Bolonha.

LINHA DO TEMPO DO PROCESSO DE BOLONHA

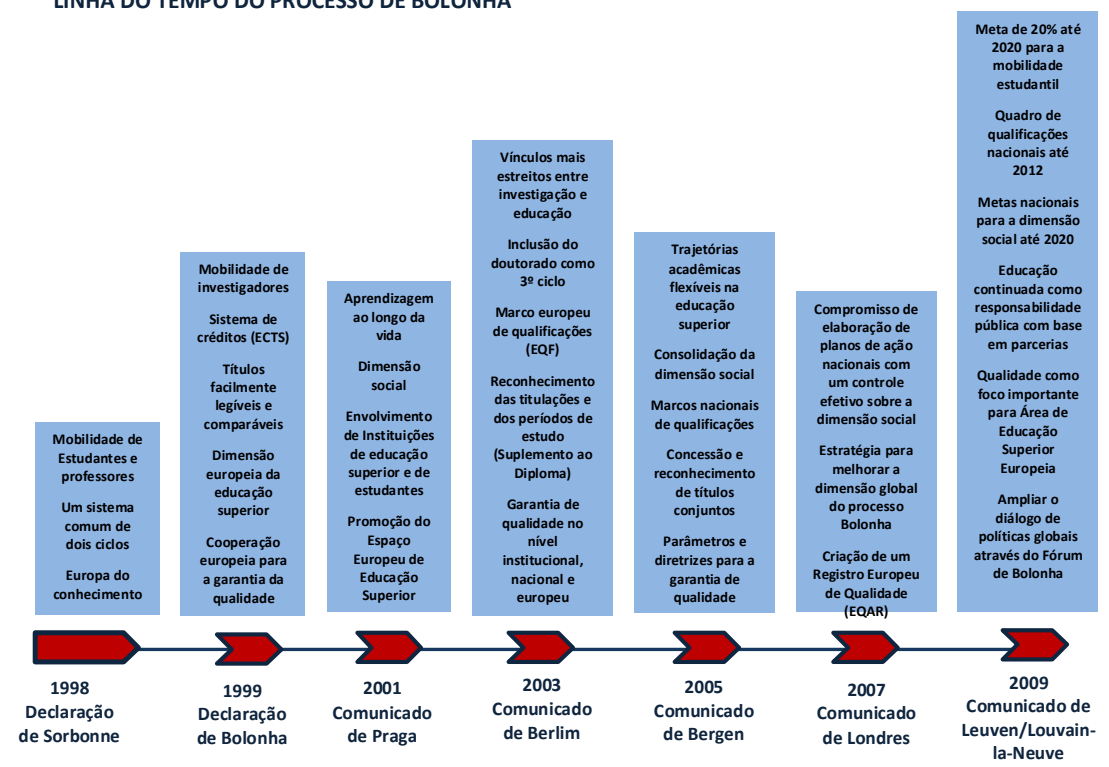

De modo geral, essas orientações devem ser entendidas como uma política pública européia para a educação superior. Em resumo, as principais linhas da proposta de reforma do Processo de Bolonha são:

Implantação de um sistema de ciclos;

Implantação de um sistema de créditos (ECTS);

Incentivo à mobilidade discente e docente;

Promoção de estruturas comuns para garantia da qualidade;

Cooperação para a promoção do espaço europeu de educação superior.

A seguir serão apresentadas as principais características de cada item de reforma proposto.

\section{Sistema de ciclos}

A introdução dos três ciclos básicos de formação (bachelor, master 
e doutorado) são uma das características principais da proposta de reforma do Processo de Bolonha. Os ciclos foram uma das soluções encontradas para promover e facilitar a mobilidade e o reconhecimento de qualificações para a harmonização das estruturas de educação superior européia (Erichsen, 2007, p.8). Assim, todos os países signatários da Declaração de Bolonha deverão ter, até 2010, um sistema de educação superior organizado nesses três ciclos (bachelor, master e doutorado).

O bachelor deve preparar os estudantes para o mercado de trabalho europeu, oferecendo um nível de qualificação apropriado. Este ciclo deve ter a duração de, pelo menos, três anos (máximo de 4 anos). Ressalta-se que as decisões e recomendações do Processo de Bolonha são para que não haja somente uma renomeação de antigos cursos e currículs, mas sim a formação de novos cursos que atendam as exigências de formar, nesse período de tempo, profissionais para o ingresso no mercado de trabalho.

O segundo ciclo, denominado de master, deve ter a duração entre um ano e meio a dois anos de formação (excepcionalmente pode durar apenas um ano). Esse segundo ciclo é entendido como complementar ao primeiro, mantendo uma relação com a formação para o mercado de trabalho, mas com maior ênfase para a pesquisa.

O doutorado foi incluído como um terceiro ciclo na proposta inicial de reforma e ficou decidido que permaneceria exclusivo das universidades. Este ciclo foi adotado somente em 2003, com o objetivo de criar uma ponte entre o Espaço Europeu de Educação Superior e o Espaço Europeu de Pesquisa. O Comunicado de Bergen (2005), estabeleceu que a duração desse terceiro ciclo poderá variar entre 3 a 4 anos letivos. Acordos entre áreas de conhecimento e órgãos profissionais, de cada país, definem a quantidade de créditos necessários para a formação. A principal característica desse ciclo é a formação de pesquisadores nas mais diversas áreas.

A implantação do sistema de ciclos na educação superior européia não significa que foram introduzidos conteúdos comuns a cada ciclo. Ou seja, um bachelor em economia numa universidade alemã pode ser tão semelhante ou diferente em seu currículo quanto outro curso de bachelor na Alemanha ou fora dela. Isso significa que a harmonização em termos de nomenclatura (bachelor, master e doutorado) e tempo de 
formação (3-2-3 anos) não implica em conteúdos comuns para cursos numa mesma área de conhecimento.

A formação dos estudantes no bachelor, específica e voltada para o mercado de trabalho é sucedida pelo master e doutorado, onde deverá ocorrer um aprofundamento do conhecimento das áreas cursadas e uma maior ênfase para a formação de pesquisadores. No entanto, as IES reconhecem que permanece um problema pelo fato dos dois ciclos não serem definidos com precisão quanto aos conteúdos (não há currículos mínimos estabelecidos, nem diretrizes curriculares para os cursos) (Flickinger, 2006).

O que é certo, é que há um enorme consenso de que as duas primeiras conclusões qualificam para o ingresso no mercado de trabalho. O BA, como algo distinto com relação ao MA, e não menor (Erichsen, 2007, p.11). Ou seja, já o primeiro ciclo é reconhecido como apropriado para a qualificação. Assim, estudantes de graduação deveriam ter acesso a uma diversidade de programas incluindo oportunidades para estudos multidisciplinares, para o desenvolvimento da proficiência em línguas e para a habilidade no uso de novas tecnologias da informação.

Antes da Declaração de Bolonha já existia em alguns países uma estrutura de ciclos, pelo menos em alguns campos. O desafio era ampliar essa prática e aumentar a convergência entre os distintos modelos existentes.

A partir de 1999, os países signatários de Bolonha passaram a introduzir a nova estrutura e até 2009 ela estava amplamente implementada na maioria das universidades. No entanto, algumas áreas como medicina, direto, por exemplo, seguem oferecendo cursos com maior prazo.

A figura a seguir representa em termos médios as transformações dos sistemas de ensino superior da França, Alemanha, Inglaterra e Portugal, com a introdução dos novos modelos. 
Figura 2: Estruturas dos sistemas de educação (França, Alemanha, Inglaterra, Portugal).

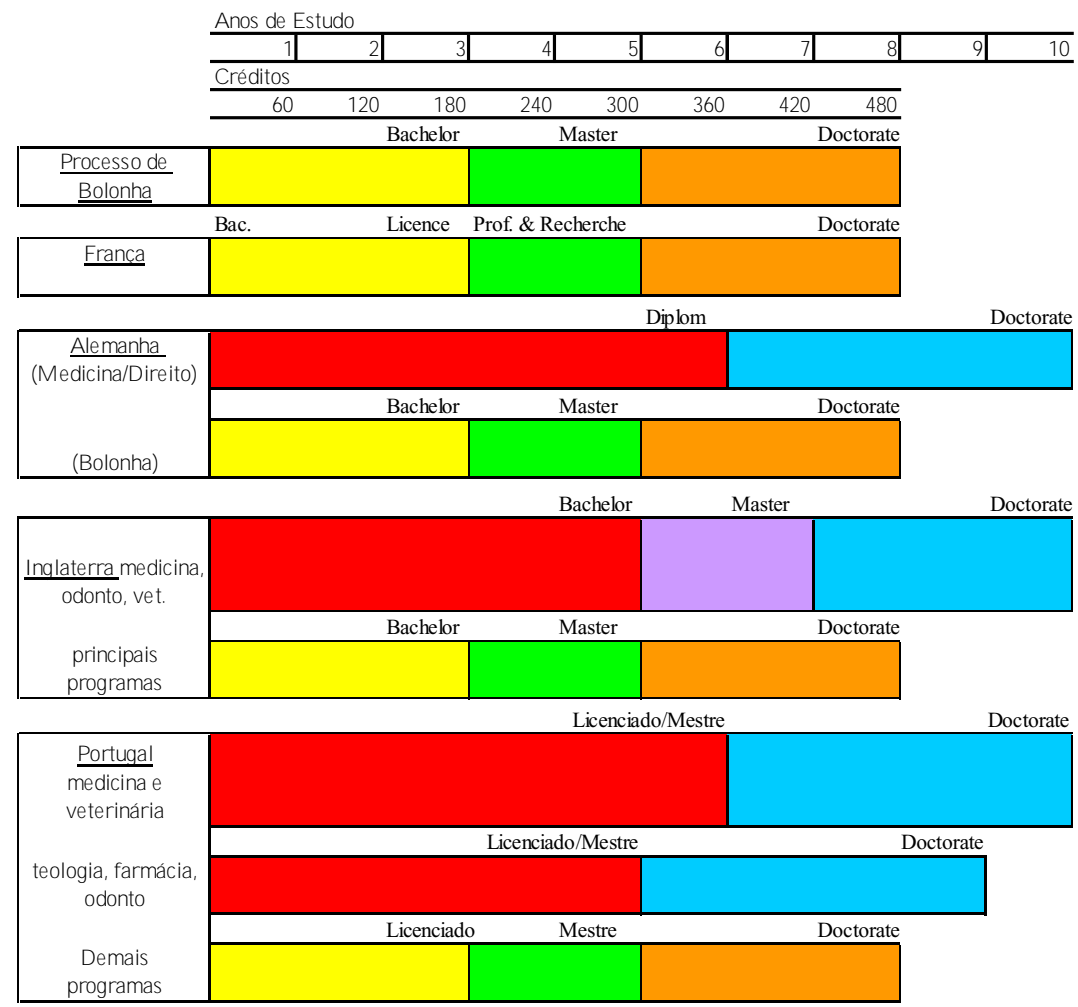

Fonte: Pesquisa "As transformações dos sistemas de educação superior no Brasil e na Europa e as perspectivas da cooperação acadêmica internacional" coordenada pela professora Dr ${ }^{\mathrm{a}}$ Clarissa Eckert Baeta Neves, 2006-2008 (apoio CNPq).

\section{Sistema de créditos}

Além da introdução dos ciclos e complementar a eles foi importante, para a consolidação da Área Européia de Educação Superior, a implantação de um sistema de créditos para a promoção do reconhecimento dos períodos de estudo. O sistema de créditos ECTS é uma das pedras fundamentais para a comparabilidade e mobilidade entre cursos, instituições e currículos. Em conjunto com o Suplemento ao Diploma (documento 
que detalha as habilidades e competências adquiridas ao longo de um período de estudo) o sistema de créditos forma o 'currículo' base para a mobilidade estudantil européia. Os cursos, atrelados a qualquer um dos três ciclos propostos pelo processo de Bolonha devem corresponder ou permitir a comparabilidade a partir dos créditos ECTS. Há certa flexibilidade para a quantidade de créditos necessários para a formação do primeiro e segundo ciclo. De modo geral o primeiro ciclo corresponde a 180 a 240 créditos ECTS (3 a 4 anos) seguido de um segundo ciclo que varia entre 60 a 120 créditos (1 a 2 anos). O número de créditos necessários a cada ciclo está relacionado à formação e aos objetivos que as instituições e os cursos almejam. Em casos nos quais o primeiro ciclo é realizado com 240 créditos ( 4 anos), segue-se um segundo ciclo de 60 créditos (1 ano). É sugerido que a formação nos dois primeiros ciclos não ultrapasse 5 anos ou 300 créditos. O terceiro ciclo, o doutorado, como foi visto anteriormente, não possui um número de créditos associado a ele.

A introdução dos ciclos e a implantação do sistema de créditos são os instrumentos essenciais para a mobilidade de estudantes e docentes na Área Européia de Educação Superior. A partir dos ciclos estabeleceramse os quadros de qualificações.

\section{Qualificações de cada Ciclo}

O quadro de qualificações ou estruturas gerais de qualificação foi elaborado a partir de resultados ou competências que os alunos devem desenvolver para completar cada um dos três ciclos da educação superior. A adoção desse quadro comum aos países envolvidos no processo se deu em 2005, na conferência de Bergen. A proposta dessa estrutura foi a de criar a possibilidade de comparação entre os diferentes sistemas, permitindo uma harmonização de resultados (habilidades e/ou competências dos alunos) sem implicar em homogeneização programática, promovendo a diferenciação de objetivos para cada ciclo, diferenciando níveis de aprendizagem e de capacidade ${ }^{11}$.

11 Fonte: http://www.ond.vlaanderen.be/hogeronderwijs/bologna/documents/QF-EHEAMay2005.pdf 
As qualificações que designam a conclusão do primeiro ciclo incluem:

- Demonstração de conhecimento e entendimento em uma área de estudo que tem por base a educação secundária, mas apresenta alguns conhecimentos avançados da área;

- Capacidade de aplicação dos conhecimentos adquiridos, que demonstrem formação profissional e competências para a elaboração e sustentação de argumentos, e resolução de problemas na área de estudo;

- Capacidade coletar e interpretar dados relevantes da área de estudo assim como emitir julgamentos que incluem reflexão sobre questões relevantes de natureza social, científica e/ou ética;

- Capacidade de comunicar informações, idéias, problemas e soluções para audiências de especialistas e não-especialistas sobre os assuntos estudados;

- Desenvolvimento de habilidades de estudo que permitam o aprofundamento do conhecimento adquirido com maior grau de autonomia.

- As qualificações que designam a conclusão do segundo ciclo incluem:

- Demonstração de conhecimento e entendimento que reforça e/ou amplia os conhecimentos tipicamente relacionados ao primeiro ciclo e proporciona uma base para a originalidade no desenvolvimento e/ou aplicação de idéias dentro de um contexto de investigação;

- Capacidade de aplicação do conhecimento e das habilidades de resolução de problemas em ambientes novos ou não-familiares dentro de contextos mais amplos relacionados ao campo de estudo;

- Habilidade para integrar conhecimento, lidar com a complexidade e formular julgamentos com informações incompletas ou limitadas, mas que inclui reflexão sobre responsabilidades éticas e sociais relacionadas à aplicação do conhecimento e decisões;

- Capacidade de comunicar conclusões, conhecimento e a lógica subjacente a estes, para audiências de especialistas e não-especialistas, de forma clara e inequívoca;

- Aquisição de competências que permitam continuar a estudar de forma autodirigida ou autônomas.

- As qualificações que designam a conclusão do terceiro ciclo incluem: 
- Demonstração de um entendimento sistemático de um campo de estudo e competência no uso de métodos e técnicas associadas a esse campo;

- Habilidade de conceber, implementar e adaptar um processo significativo de investigação acadêmica com integridade;

- Contribuir através de uma pesquisa original, de modo a alargar a fronteira do conhecimento, com o desenvolvimento de um conjunto significativo de trabalhos, alguns dos quais aptos para publicação nacional ou internacional;

- Capacidade de análise crítica, avaliação e síntese de novas e complexas idéias;

- Capacidade de comunicar para pares, para a comunicada acadêmica e a sociedade em geral sobre suas áreas de especialidade;

- Espera-se capacidade de promover, em âmbito acadêmico e profissional, avanços culturais, sociais e tecnológicos numa sociedade baseada no conhecimento.

\section{Suplemento ao Diploma (DS)}

As habilidades e capacidades atribuídas a cada ciclo através do quadro de qualificações contribuem para formar o currículo do estudante. Essas habilidades e capacidades são registradas na forma do Suplemento ao Diploma. Esse documento atesta a aquisição dessas competências e possui um caráter descritivo complementar aos Diplomas adquiridos. Essa é uma das formas para promover a comparabilidade da formação entre cursos. Cursos diferentes podem assim ser comparados a partir das capacidades que proporcionam. Da mesma forma cursos semelhantes, de mesma área ou disciplina, podem se diferenciar ao promover diferentes enfoques, especialidades e capacidades. A comparabilidade dos estudos realizados em diferentes situações é reforçada, aqui, pela referência ao histórico descritivo da formação do estudante. A adoção de quadros de qualificações comuns e do Suplemento ao Diploma são as principais formas adotadas para promover a organização da educação e o diálogo entre as necessidades dos alunos, a formação básica e a preparação profissional ${ }^{12}$.

12 Fonte: http://ec.europa.eu/education/policies/rec_qual/recognition/diploma_en.html 


\section{Qualidade e Avaliação}

Outra linha de ação central do Processo de Bolonha é a preocupação com a garantia de qualidade, com vistas a alcançar os objetivos, da promoção da mobilidade e o incremento da competitividade internacional do Espaço Europeu de Educação Superior. Foi neste contexto que os Ministros que tutelam a educação superior propuseram a adoção de formas de garantia da qualidade acadêmica e de sistemas de avaliação interna e externa e de acreditação.

Segundo o Comunicado de Berlim, atribuem-se, pelo menos, dois sentidos à expressão garantia de qualidade: desenvolver a qualidade de um curso ou instituição e dar garantias dessa qualidade a terceiros. A designação mais corrente para o processo relativo ao primeiro é avaliação, enquanto, para o segundo, é acreditação (Erichsen, 2007, p.13).

Uma vez que a autonomia institucional é uma tradição européia fortemente enraizada, foi decidido que cada instituição de educação superior deverá promover sistemas próprios de garantia e de desenvolvimento de qualidade. Esses sistemas deverão ser passíveis de certificação por entidades externas à instituição: "Os sistemas de certificação deverão avaliar os programas e instituições através de: avaliação interna (nacional); avaliação externa (realizada por países parceiros); participação dos estudantes; e publicação de resultados" (Comunicado de Berlim, 2003).

Os vários sistemas nacionais devem adotar procedimentos comparáveis e cooperar através da Rede Européia para a garantia da Qualidade na Educação Superior (ENQA). Essa Rede reúne os principais organismos de acreditação, governamentais e privados dos Estadosmembros, com a finalidade de fazer circular informação, experiências, boas práticas e novos desenvolvimentos no campo da certificação da qualidade. No âmbito de Bolonha foram desenvolvidos um conjunto de medidas, procedimentos e orientações da certificação de qualidade, assim como da criação de um quadro comum de referência.

Já a avaliação, refere-se a instituições, pesquisas realizadas, cursos oferecidos, gestão, serviços, etc. É antes um processo auto-referencial. Assim, acreditação/certificação (para fora) e avaliação (para dentro e para fora) são congruentes sob vários aspectos. Segundo Ericksen (2007) 
o que importa, em ambos os procedimentos, é que devem servir para a garantia da qualidade do sistema de educação superior.

Através do Processo de Bolonha pretendeu-se que a formação fosse assumida como uma etapa ao longo da vida (Lifelong Learning), incluída a partir do Comunicado de Praga em 2001 e reafirmada nos demais comunicados. Como tal, a aprendizagem não deveria se esgotar na estrutura nacional de educação, mas englobar todo um conjunto de outras atividades de formação ${ }^{13}$.

A educação continuada afeta, assim, vários aspectos do espaço europeu de educação superior, nomeadamente: programas de mobilidade; e-learning; investigação; educação vocacional; reconhecimento de qualificações. E tem ainda um papel central no alcance do objetivo de "tornar a União Européia na economia do conhecimento mais competitiva e dinâmica no mundo”, objetivo este conhecido por Estratégia de Lisboa estabelecida no encontro do Conselho Europeu em Lisboa no ano 2000.

Para a concretização desse "espaço de aprendizagem” foi proposta a transformação dos sistemas tradicionais de educação, com a criação de parcerias entre os prestadores de serviços educativos (como as escolas, universidades, institutos politécnicos, etc.) e a sociedade civil (empresas, associações locais, etc.). Também foi proposto identificar as necessidades do mercado de trabalho e tornar as ofertas de aprendizagem mais acessíveis, facilitando a aprendizagem no local de trabalho.

A utilização do sistema de créditos de acumulação ECTS e do Boletim de Registro Acadêmico deverá facilitar o reconhecimento destas formações em qualquer dos países signatários, tornando os percursos acadêmicos mais flexíveis. Destacam-se, ainda, como pontos em discussão a cobrança de taxas, a criação de infra-estrutura para educação continuada, a educação continuada de natureza científica e a garantia da qualidade (Erichsen, 2007, p.17).

\section{Mobilidade}

A mobilidade é um dos objetivos principais do processo de Bolonha. A elaboração de uma estrutura de educação superior comum a diver-

13 Fonte: http://cicic.ca/docs/qf/eqf.en.pdf 
sos países baseada em ciclos, a implantação de um sistema europeu de acúmulo e transferência de créditos, um quadro de qualificações relativas a cada ciclo, são medidas que tem por objetivo proporcionar a mobilidade de estudantes, professores e profissionais graduados (Declaração de Sorbonne, 1998; Declaração de Bolonha, 1999).

O processo de Bolonha, com sua proposta de harmonização dos sistemas de educação superior, tem sua base numa ampla tradiçao européia, a da mobilidade acadêmica. Exemplo classico é Erasmus de Rotterdam (1466-1536). Nascido em Rotterdam, ele estudou em Paris, fez seu doutoramento em Turin, desenvolveu atividades docentes em Cambridge, foi pesquisador na Universidade de Freiburg e viveu seus últimos anos em Basel. Erasmus corporificou já no sécculo 16, o verdadeiro ideal de educação e pesquisa. Ele foi o protótipo do moderno homem educado (Frey, 2009).

No entanto, ainda existem muitas barreiras que impedem uma real mobilidade acadêmica européia. De acordo com o Bologna FollowUp Group ${ }^{14}$, os maiores impedimentos estão relacionados à obtenção de vistos e permissões de residência e trabalho, o reconhecimento de qualificações, incentivos financeiros (bolsas e empréstimos para estudantes), sistemas de seguridade social, programas conjuntos e currículos flexíveis. Apesar dos avanços apresentados nas discussões gerais no âmbito do processo de Bolonha, as transformações devem ser aprovadas em cada país, internamente. Não há uma automática adoção das medidas aprovadas nos encontros e reuniões e sim a aceitação do compromisso de mudança.

A busca por soluções e aprimoramentos para a garantia da mobilidade internacional pode ser observada a partir das diversas iniciativas por parte de instituições e associações, como a Campanha da Mobilidade Let's Go promovida pela Education International (EI) e a União dos Estudantes Europeus (European Student's Union - ESU) ${ }^{15}$. O maior suporte para a efetivação da mobilidade ainda reside nos programas de financiamento promovidos pela União Européia. Os principais programas de mobilidade acadêmica da União Européia são: Comenius,

14 http://www.ond.vlaanderen.be/hogeronderwijs/bologna/actionlines/mobility.htm, 03/09/2008.

15 Fonte: http://www.letsgocampaign.net/ 
Erasmus e Erasmus Mundus, Leonardo da Vinci, Grundtvig e Tempus. Os programas voltados, específicamente, para a educação superior são: Erasmus, Erasmus Mundus e Tempus.

- Erasmus (educação superior);

Erasmus é o principal programa da União Européia para a promoção da mobilidade acadêmica, tanto de professores quanto de estudantes e quadros administrativos das instituições de educação superior. De acordo com o portal da UE, a cada ano mais de 200.000 pessoas são beneficiadas pelo programa, com a possibilidade de estudar e trabalhar através dos países europeus. Aproximadamente 3 milhões de pessoas foram atingidas através das ações de mobilidade estudantil desde o início do programa Erasmus.

- Erasmus Mundus

Erasmus Mundus tem como base as realizações alcançadas com o programa Erasmus, mas volta-se para estudantes de regiões fora da Europa. Sua atuação dá-se na forma de programa de mobilidade e de cooperação. Seu objetivo principal é a promoção da União Européia como centro de excelência mundial no ensino.

- Tempus: Modernizing higher education

Tempus é um programa voltado para a modernização e desenvolvimento da educação superior dos países adjacentes a União Européia. Ele foi estabelecido depois da queda do muro de Berlim. As regióes beneficiadas são os Bálcãs, Europa Oriental, Ásia Central, Norte da África e o Oriente Médio.

Dos três programas, o de maior destaque é o programa Erasmus. De acordo com Eurydice ${ }^{16}$, a maior parte dos estudantes envolvidos com o programa de Erasmus de mobilidade acadêmica durante o período 1987/88 - 2006/07 são provenientes de cinco países (Alemanha 15,64\%, França - 15,60\%, Espanha - 14,01\%, Itália - 11,31\% e Reino Unido com 9,34\% do total do período). Estes mesmos países também

16 Banco de dados sobre os sistemas de educação superior europeus http://ec.europa.eu/ education/programmes/llp/erasmus/statisti/table1.pdf 
são os responsáveis pela maior parte da hospedagem dos alunos envolvidos com o referido programa de mobilidade. Essa concentração indica limites para a efetiva mobilidade de estudantes e docentes através da Europa, em especial no total dos 48 países parceiros do programa de reformas do Processo de Bolonha.

A tabela 1 abaixo indica a mobilidade de estudantes de um país para outro. Alemanha, França, Espanha, Itália estão entre os países com mais alta mobilidade. No Reino Unido observa-se um decréscimo de número de estudantes estrangeiros nos últimos anos.

Tabela 1: Mobilidade de estudantes do programa Erasmus, Alemanha, Itália, França,Espanha e Reino Unido - 2001-2007

\begin{tabular}{|c|c|c|c|c|c|c|c|c|c|c|}
\hline \multirow[b]{2}{*}{ Ano } & \multicolumn{2}{|c|}{ Alemanha } & \multicolumn{2}{|c|}{ Itália } & \multicolumn{2}{|c|}{ França } & \multicolumn{2}{|c|}{ Espanha } & \multicolumn{2}{|c|}{ Reino Unido } \\
\hline & $\begin{array}{l}\text { Estudantes } \\
\text { do pais no } \\
\text { estrangeiro }\end{array}$ & $\begin{array}{c}\text { Estudantes } \\
\text { estrangeiros } \\
\text { no pais }\end{array}$ & $\begin{array}{l}\text { Estudantes } \\
\text { do pais no } \\
\text { estrangeiro }\end{array}$ & $\begin{array}{c}\text { Estudantes } \\
\text { estrangeiros } \\
\text { no pais }\end{array}$ & $\begin{array}{l}\text { Estudantes } \\
\text { do pais no } \\
\text { estrangeiro }\end{array}$ & $\begin{array}{c}\text { Estudantes } \\
\text { estrangeiros } \\
\text { no pais }\end{array}$ & $\begin{array}{l}\text { Estudantes } \\
\text { do país no } \\
\text { estrangeiro }\end{array}$ & $\begin{array}{c}\text { Estudantes } \\
\text { estrangeiros } \\
\text { no pais }\end{array}$ & $\begin{array}{l}\text { Estudantes } \\
\text { do pais no } \\
\text { estrangeiro }\end{array}$ & $\begin{array}{c}\text { Estudantes } \\
\text { estrangeiros no } \\
\text { pais }\end{array}$ \\
\hline 2001 & 15872 & 15275 & 13253 & 8836 & 17161 & 17642 & 17158 & 16979 & 9020 & 19339 \\
\hline 2002 & 16626 & 15503 & 13950 & 9863 & 18149 & 17807 & 17403 & 18826 & 8475 & 17619 \\
\hline 2003 & 18482 & 16106 & 15225 & 10982 & 19465 & 18833 & 18258 & 21302 & 7973 & 16994 \\
\hline 2004 & 20688 & 16863 & 16829 & 12713 & 20981 & 20260 & 20034 & 24049 & 7539 & 16621 \\
\hline 2005 & 22427 & 17273 & 16440 & 13370 & 21561 & 20519 & 20819 & 25511 & 7214 & 16266 \\
\hline 2006 & 23848 & 17889 & 16389 & 14591 & 22501 & 21436 & 22891 & 26625 & 7131 & 16395 \\
\hline 2007 & 23884 & 17878 & 17195 & 14779 & 22981 & 20673 & 22322 & 27464 & 7235 & 16508 \\
\hline
\end{tabular}

Ainda não há dados consolidados sobre mobilidade. Os dados disponíveis revelam, no entanto, alguns fatos significativos. O principal é que há muitas diferenças entre os países com relação à mobilidade e de um modo geral ela ainda está muito aquém do esperado. De 18 países, menos de $3 \%$ dos estudantes tem alguma experiência de estudo em uma instituição estrangeira. A maior mobilidade dá-se em tres países, Alemanha, França e Reino Unido. Desta maneira, o impacto que a reforma da estrutura de títulos (ciclos), como parte do processo de Bolonha, tem sobre os fluxos de mobilidade dos estudantes, ainda é bastante desconhecido.

\section{Considerações Finais}

Frente às transformações das últimas décadas do século $\mathrm{XX}$, a Europa experimentou mudanças significativas na educação superior. Na década de 1990, o tema da educação superior surge na agenda das organizações macro-políticas européias, tendo por foco a promoção de 
uma maior harmonização entre os países para incentivar e promover a educação superior.

Os debates sobre a educação superior, originaram um processo de discussão com desdobramentos em múltiplos níveis de decisão. Mobilizaram-se para esse debate, Ministros da Educação dos países europeus, associações de universidades, conselhos de reitores, entre outros atores. Nesse processo estabeleceram-se parâmetros para uma reforma, que, no entanto, permaneceu aberta à incorporação de novas dimensões. No decorrer do processo foram se consolidando as principais linhas (ciclos, créditos, qualificação, qualidade, avaliação, mobilidade e educação continuada) na pauta das formulações de políticas nacionais.

De acordo com Erichsen (2008) ${ }^{17}$, esperava-se que o número de países participante da proposta do Processo de Bolonha fosse reduzido ${ }^{18}$. Segundo ele, acreditava-se no início de um processo de harmonização, que fosse levado a cabo por um pequeno grupo de países. Dos quatro países presentes na primeira reunião na universidade de Sorbonne (1998), pelo menos dois, França e Reino Unido, não encontrariam dificuldades para a realização dos objetivos de harmonização dos sistemas de educação nos moldes propostos. O sistema de educação superior do Reino Unido já atuava a partir de dois ciclos de formação, enquanto a França possuía um sistema de educação muito mais diversificado, com mais graus, sendo facilmente readaptável a um modelo mais simples. O caso da Alemanha, mesmo apresentando-se como o de maior complexidade, era detentor de uma ampla vontade política por mudanças em seu sistema. Já em 1998, havia sido aprovada a Lei da Educação Superior, que previa a introdução de novos cursos ao molde de dois ciclos, bachelor e master (Neuser,2006).

De certo modo, com o crescimento do número de países envolvidos, aumentaram as dificuldades para a concretização da Área Européia de Educação Superior. À medida que outros sistemas de educação superior foram incorporados ao Processo de Bolonha, novos elementos acabavam por serem adicionados às linhas de ações. $\mathrm{O}$ aumento do número

17 Palestra realizada na Faculdade de Educação da Universidade Federal do Rio Grande do Sul em Abril de 2008.

18 O professor foi um dos membros participante da primeira reunião realizada em Sorbonne, como presidente do Conselho Europeu de Reitores. 
de países ampliou os pontos do debate e pulverizou as discussões. No entanto, essa dificuldade tem sido superada com o consenso da necessidade de reforma e a celeridade com que estão sendo implantadas as principais linhas nos sistemas nacionais de educação superior.

O que se observa na Europa é que os arranjos feitos, não produziram comprometimento significativo do espírito original do chamado Processo de Bolonha. Resistências são muito menores do que se poderia esperar, de países com forte tradição de autonomia universitária. Há certo consenso de que os modelos europeus mostravam real esgotamento. O custo é muito alto, a ineficiência muito grande (tempo de permanência, evasão, pouca atratividade etc.) e, cada vez mais, mostravam a incapacidade de fazer frente ao sucesso de modelos de países centrais da nova economia globalizada.

A Europa confessa, com essa reforma, só ver chances de sucesso se aprofundar a integração e a criação de um espaço único de formação de recursos humanos e de produção de conhecimento. Para uma região que adotou uma moeda única, já fez uma tentativa de instituir uma constituição única, reformar a educação superior era uma tarefa necessária e viável. Os avanços obtidos na última década (1999 - 2009), confirmam o empenho dos paises envolvidos, na consecução das metas estipuladas na reforma.

\section{Referências bibliográficas:}

ERICHSEN, H.U. Tendências Européias na graduação e na garantia da qualidade. Sociologias, ano $9, \mathrm{n}^{\circ} 17$, Porto Alegre: UFRGS, IFCH, 2007, p. 22-49.

FLICKINGER, H.G. Impactos da missão da universidade alemã frente às transformações exigidas pelo processo de Bolonha. Palestra proferida no Seminário Internacional da Fundação Humboldt. Porto Alegre: PUCRS, novembro, 2006.

FREY, R. Tradition und Neugesatltung der deutschen Universität. Bologna-Reform als Irrweg? Palestra realizada na UFRGS. Porto Alegre. 20.11.2009.

GROSJEAN, E. Forty Years of Cultural Cooperation at the Council of 
Europe, 1954-94. European Education 31, nº1 p. 11-37, 1999.

KOPPE, Leonardo Renner. Transformações da educação superior na Europa: A reforma da educação superior na Alemanha pósProcesso de Bolonha. Dissertação de Mestrado. Porto Alegre; PPGS/ UFRGS, 2008.

MORHARD, B. Lehren und Lernen mit ERASMUS in Europa. Bonn: DAAD, 2005.

NEUSER, W. O Processo de Bolonha e sua implementação na Alemanha. In: Inovação e Empreendedorismo na Universidade. (Orgs.) Audi, J.L.N./ Morosini M.C. Porto Alegre: EDIPUCRS, 2006.

NEVES, C.E.B. O Processo de Bolonha e as Transformações dos Sistemas de Educação Superior na Europa. 2006.

PFETSCH, F.R. A União Européia: história, instituições, processos. Brasília: Editora Universidade de Brasília: Imprensa Oficial, 2001.

WITTE, J.K. Change of degrees and degrees of change: comparing adaptations of european higher education systems in the context of the bologna process. UNITISK, Czech Republik, 2006.

\section{Documentos e sites consultados:}

UK HE Europe Unit, Guide to Bologna Process. 2005.

UK HE Europe Unit, Guide to Bologna Process 2 edition. 2006.

Conselho Europeu de Lisboa, Estratégia de Lisboa, 2000.

Comissão das Comunidades Européias. Comunicação da Comissão: Investir eficazmente na educação e na formação: um imperativo para a Europa. Bruxelas, 2003.

Comissão das Comunidades Européias. Comunicação da Comissão: O papel da universidade na Europa do conhecimento. Bruxelas, 2003.

Comissão das Comunidades Européias. Comunicação da Comissão: “Educação \& Formação para 2010” A urgência das reformas necessárias para o sucesso da estratégia de Lisboa. Bruxelas, 2003.

BFUG. From Berlim to Bergen. General Report of the Bologna Follow-Up Group to the Conference of European Ministers Responsible for Higher 
Education. Bergen: 19-20 May 2005.

EURYDICE. Focus on the structure of higher education in Europe. National trends in the Bologna Process - 2006/07 Edition / Eurydice Brussels: Eurydice, 2007, 2009, 2010.

European Higher Education in a Global Setting. Norwegian Ministry of Education and Research, Oslo, September, 2007.

Bologna Follow-up Group. Bologna Process: Stocktaking Report 2007. Report to the Ministerial Conference in London, May 2007.

Recebido em 10 de agosto de 2009.

Aceito em 25 de outubro de 2009. 